\title{
Building a Teaching and Learning Community: A Blended Approach to Providing Support
}

\author{
Darlene Spracklin-Reid, Lesley James, Kelly Hawboldt, Salim Ahmed and John Shirokoff \\ Faculty of Engineering and Applied Science \\ Memorial University of Newfoundland \\ darlenesr@mun.ca, ljames@mun.ca,khawboldt@mun.ca, sahmed@mun.ca, shirokof@mun.ca
}

\begin{abstract}
Creating an active teaching and learning community can be challenging but at Memorial University, a blended approach is proving to be effective. Through regular face-to-face group discussions, one-on-one coaching sessions, and online sharing and support, an active community of teachers and learners is being created in Process Engineering. This paper details a practical approach to engaging students and faculty in program development, encouraging dialogue about best-practices in teaching and learning, sharing resources, and providing support and mentorship.
\end{abstract}

\section{Introduction}

The shift from an emphasis on teaching to an emphasis on learning means the goal of formal education is not to ensure that students are taught, but rather to ensure they learn. The result of this type of shift is the evolution of teaching and learning, or professional learning, communities that focus on improving learning in the post-secondary environment [1]. Developing a teaching and learning community is an action that is positively perceived by both educators and administrators. Studies clearly demonstrate that a learning community model has a positive impact on both teaching and learning [2].

Educators who create teaching and learning communities realize that a collective effort can facilitate the overall improvement of teaching and learning. They are focused on becoming a group of collaborative individuals through reflective dialogue and taking a pedagogical leadership role [3]. Professional learning communities create structures to promote a collaborative culture that includes systematic processes in which educators work together to analyze and improve their pedagogical skills. They engage in reflective questioning that promotes deep team learning and leads to higher levels of student achievement [1].

From a social-constructivist point of view, learners make meaning as they negotiate with other participants through dialogues and conversations. Collaborating as a professional learning community gives faculty an opportunity to learn together and create pedagogical knowledge. The opportunity to interact, share, construct and negotiate meaning leads to knowledge construction [4].

Creating a teaching and learning community in a busy post-secondary environment can be challenging. Faculty members have a variety of roles and commitments that they must balance along with teaching. Although the desire to be a more effective educator is common, time to devote to pursuing this goal is not always readily available. In order to collaborate in a busy, pressed-for-time, environment, a blended approach was taken to encourage faculty members to discuss best teaching practices and to share their experiences and reflections.

Few educators assert that working in isolation is the best strategy for improving teaching and learning, but they do find it difficult to collaborate given time pressures, varying levels of commitment and conflicting schedules [1]. Meeting regularly in person can be an efficient way to engage in conversations about teaching and learning however, with conflicting schedules, there was concern about the sustainability of relying solely on this approach to collaboration. To make the group accessible and sustainable, multiple collaboration methods were implemented. The group met face-to-face regularly, an online resource-sharing site was created and one-on-one teaching coaching sessions were offered. Both face-to-face and online components can help educators develop their pedagogical knowledge, content skills, and instructional practices in engineering [4].

Adding an online component to the teaching and learning community offers one solution to overcoming time constraints and providing easy access to 
professional development. Online professional development seems to be a perfect fit for the busy schedules of faculty. It is a convenient, accessible, and inexpensive method for updating pedagogical expertise [4]. Online professional development can also contribute to the development of long-term strategies for enhancing the pedagogical skills of educators. Unlike short-term workshops, online professional development can provide ongoing learning, mentoring and networking opportunities [5].

\section{Results and Discussion from Creating a Teaching and Learning Community}

The Process Engineering Teaching and Learning Community met bi-weekly, or weekly when required. Topics such as formative assessment were discussed and experiences were shared with the group. The group also worked collaboratively to create a concept map for the program, which led to discussions about sequencing, redundancies, and opportunities to introduce new topics. Discussion sessions were recorded and suggestions noted for sharing in the online forum. Suggestions for further research were passed along to the Faculty of Engineering's instructional designer.

The face-to-face meetings of the Process Engineering Teaching and Learning Community presented an opportunity to collaborate on accreditation-related projects. Memorial University's approach to the Canadian Engineering Accreditation Board's criteria for demonstrating the attainment of specified graduate attributes is based on establishing a comprehensive set of course-based learning outcomes. These course-based learning outcomes collectively comprise the program outcomes so Process Engineering worked collaboratively to establish outcomes for each course in the discipline. Improving the sequencing of topics using a topic map was discussed (Spracklin-Reid et. al, 2013), streamlining outcomes occurred and opportunities for further exploration of concepts were identified as these outcomes were established.

One of the critical success factors in creating the teaching and learning environment was the engagement of all faculty members. Unlike a lunch and learn or a seminar on a specific teaching and learning topic, the teaching and learning community engaged faculty. This fundamental difference was critical in achieving such high levels of participation. The teaching and learning community was a dynamic environment where faculty not only learned but participated, collaborated, and in a time effective manner created content and methodologies to better the Process Engineering program. The sharing of ideas and responsibilities to create accreditation related content or work on continuous improvement created an environment where the sharing of individual ideas was valued. The face-to-face meetings were successful because objectives were set and the meeting times were used to effectively realize the outcomes. Another critical success factor in creating such a positive teaching and learning community was the use of a facilitator. Be it a faculty member or, in this case, the senior instructional developer, the role of a facilitator is to help define objectives, shape dialogue and discussion, and realize the goals that are measurable, achievable, ...(there is an acronym for it, but I can't remember). A facilitator helps to set objectives, align discussion and consolidate participants' feedback into measured outcomes without much effort being required by individual faculty outside the meeting time.

As questions, answers and resources were being generated, the need to collaborate and share resources became evident. A course shell, Process Engineering Supports, was created in the learning management system, Desire2Learn (D2L), to serve as a space for collaboration.

Process Engineering Supports is divided into several modules. The Graduate Attributes: Tools for Teaching and Learning module has a section for each graduate attribute that contains information about teaching, learning and assessment of that attribute. For example, the communication section has resources for teaching communication skills and rubrics to assist with assessment. There are also writing guides and tip sheets available to distribute to students.

The remaining modules focus on teaching, learning and curriculum improvement. Modules on formative and summative assessment techniques were developed in response to a face-to-face collaboration session where the need for practical, easily implemented assessment techniques was identified. Faculty members and staff shared formative assessment techniques they have found effective in their own teaching and the instructional designer researched and shared additional assessment tools. The tools are available for use, modification and sharing by faculty. The summative assessment module offers assistance with traditional assessment tools such as exams, assignments, presentations and labs. It contains advice on writing multiple-choice questions and provides sample rubrics. This module also explores ePortfolios, reflective journals and self-assessments providing practical examples of implementing these techniques in engineering courses.

Process Engineering Supports also contains modules for sharing lesson plans, teaching strategies, 
multi-media resources and rubrics. There is also a continuously updated feed containing links to articles on effective teaching strategies for post-secondary environments.

Owing to the large amount of data that is placed on the Course Shell in the D2L website it is not practical to reproduce these data in this publication. However, it is practical to give the readership of this paper an idea of the content using Figure 1 which outlines a brief review of our approach, and Table 1 which gives an example of mapping the learning outcome and assessment in one of many courses in the Process Engineering program.

Figure 1: Review of our Approach

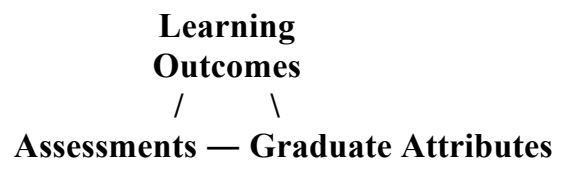

Table 1: An Example for Mapping of Learning Outcomes, Graduate Attributes and Assessment in Courses (Process Engineering Undergraduate Terms $1-8)$.

\begin{tabular}{|c|c|c|}
\hline $\begin{array}{l}\text { Learning } \\
\text { Outcome }\end{array}$ & $\begin{array}{c}\text { Graduate } \\
\text { Attribute and } \\
\text { Level }\end{array}$ & $\begin{array}{c}\text { Method of } \\
\text { Assessment }\end{array}$ \\
\hline $\begin{array}{l}\text { Identify and } \\
\text { understand the role } \\
\text { of process } \\
\text { engineering in the } \\
\text { community. }\end{array}$ & $\begin{array}{l}\text { GA08.1 } \\
\text { GA09.1 }\end{array}$ & $\begin{array}{l}\text { group activity, } \\
\text { reflective } \\
\text { ePortfolio posting }\end{array}$ \\
\hline $\begin{array}{l}\text { Create block flow, } \\
\text { process flow, } \\
\text { piping and } \\
\text { instrumentation } \\
\text { diagrams. }\end{array}$ & $\begin{array}{l}\text { GA01.2, } \\
\text { GA04.2, } \\
\text { GA05.2, } \\
\text { GA07.2 }\end{array}$ & $\begin{array}{l}\text { assignment, } \\
\text { midterm, lab }\end{array}$ \\
\hline
\end{tabular}

1 (Note: GA09.1 - means Graduate Attribute 9 at an introductory

GA01 A knowledge base for engineering

GA02 Problem analysis

GA03 Investigation

GA04 Design

GA05 Use of engineering tools

GA06 Individual and team work

GA07 Communication skills

GA08 Professionalism

GA09 Impact of engineering on society and the environment

GA10 Ethics and equity

GA11 Economics and project management

GA12 Life-long learning

\begin{tabular}{|l|l|l|}
\hline $\begin{array}{l}\text { Complete material } \\
\text { balances involving } \\
\text { chemical reactions, } \\
\text { thermodynamics } \\
\text { (reboilers/reflux } \\
\text { and recycle. }\end{array}$ & $\begin{array}{l}\text { GA01.2, } \\
\text { GA03.2 }\end{array}$ & $\begin{array}{l}\text { assignment, } \\
\text { midterm, lab, final } \\
\text { exam }\end{array}$ \\
\hline $\begin{array}{l}\text { Use HYSYS to } \\
\text { detail a PFD, } \\
\text { convert units, and } \\
\text { perform material } \\
\text { balances. }\end{array}$ & GA05.2, & labs \\
\hline $\begin{array}{l}\text { Communicate } \\
\text { technical } \\
\text { information in a } \\
\text { clear and effective } \\
\text { manner. }\end{array}$ & $\begin{array}{l}\text { GA07.2, } \\
\text { GA08.1 }\end{array}$ & $\begin{array}{l}\text { presentation, } \\
\text { project, lab, report }\end{array}$ \\
\hline $\begin{array}{l}\text { Evaluate your } \\
\text { learning style. }\end{array}$ & GA12.1 & self-quiz, \\
eportfolio
\end{tabular}

Faculty learning communities are successful at changing or providing new curricula [6] so online modules are also used to support curriculum development and continuous improvement. Sections of the online resources are used to share learning outcomes, their link to graduate attributes and the assessments used to measure them. Current curriculum and concept maps for the program are also shared on the site to provide educators and students with context. Providing context for students can improve student achievement. Students can struggle with integrating concepts when they can't see the bigger picture [7]. A program of study is greater than the sum of its parts. Seeing the complete picture is more meaningful for teachers and students than a random collection of pieces [8].

Engineering-based professional development for educators could benefit from the integration of technology, the creation of community, and the assessment of the impact on teachers' and students' knowledge, attitudes, and behaviors about engineering education [4]. Researchers have found that a process centered on classroom outcomes was successful in creating a professional learning community and a shared understanding through professional learning can positively impact student achievement [3, 9]. 


\section{Conclusion}

The Process Engineering Teaching and Learning Community proved to be a productive way to establish learning outcomes and a curriculum map for accreditation, but it also proved to be a useful tool for improving teaching and learning practices. Using a blended approach ensured that the group was able to provide the types of support that faculty wanted and needed. A blended approach helped to make the group sustainable and it continues to meet in-person and online. The online tool-kit continues to expand and the remaining engineering disciplines at Memorial University have begun the process of establishing similar teaching and learning communities using the same blended approach.

\section{References}

[1] R. DuFour, "What is a Professional Learning Community?", Educational Leadership, vol. 61, no. 8, pp. 611, 2004.

[2] V. Vescio, D. Ross, and A. Adams, "A Review of Research on the Impact of Professional Learning Communities on Teaching Practice and Student Learning", Teaching

[3] D. Andrews, and M. Lewis, " The Experience of a Professional Community: Teachers Developing a New Image of Themselves and Their Workplace. ", Educational Research, vol. 44, no. 3, pp. 237-254, 2010.

[4] W. Liu, R. Carr, and J. Strobel, "Extending Teacher Professional Development through an Online Learning Community: A Case Study", Journal of Educational Technolgy Development and Exchange, vol. 2, no. 1, pp. 99112, 2009.

[5] S. Barab, R. Kling, and J. Gray, Designing for Virtual Communities in the Service of Learning, Cambridge University Press, New York, 2004.
[6] M.D. Cox, "Introduction to Faculty Learning Communities ", New Directions for Teaching and Learning, vol. 2004, no. 97, pp. 5-23, 2004.

[7] J. Simon, " Curriculum changes using concept maps ", Accounting Education, vol. 19, no. 3, pp. 301-307, 2010.

[8] R. M. Harden, "AMEE Guide No. 21: Curriculum Mapping: A Tool for Transparent and Authentic Teaching and Learning", Medical Teacher, vol. 23, no. 2, pp. 123-137, 2001.

[9] L. Wilkerson, and D. Irby, " Strategies for Improving Teaching Practices: A Comprehensive Approach to Faculty Development ", Academic Medicine, vol. 73, no. 4, pp. 387396, 1998. 